\title{
Octavio Paz y las metáforas de la historia
}

\author{
Javier Rico Moreno
}

Resumen: En dos de sus ensayos más conocidos, El laberinto de la soledad y Posdata, Octavio Paz expuso un conjunto de ideas y reflexiones que expresan su visión de la historia, una dimensión de su pensamiento y de su obra en prosa, hasta hoy, poco explorada. Aunque hay en esos dos libros una interpretación del pasado mexicano que destaca por su sentido crítico - y autocrítico-, en un nivel más profundo se descubre la presencia de reflexiones propias de la teoría de la historia. En ambos casos destaca el recurso a la analogía y la construcción de metáforas para crear imágenes inteligibles del pasado. Desde una perspectiva historiográfica, El laberinto de la soledad y Posdata muestran la cercanía de la literatura con la historia, pero, sobre todo, la dimensión poética que subyace en la interpretación del pasado.

Aвstract: In two of his best-known essays, The Labyrinth of Solitude, and Postscript, Octavio Paz exposed a set of ideas and reflections to express his view on history, a dimension of his thought and his prose work, to date, little explored. Although there is an interpretation of the Mexican past, notable for its critically, and self-critical sense, on a deeper level that can be found in these two books, the presence of theory of history's own reflections are discovered. In both cases the resource of analogy and the building of metaphors are emphasized to create intelligible images of the past. From a historiographical perspective, The Labyrinth of Solitude and Postscript show the closeness of literature to history, but above all, the poetic dimension that underlies the interpretation of the past.

Palabras Clave: historia y poesía; Octavio Paz; El laberinto de la soledad; Posdata; metáforas de la historia.

KeYwords: History and Poetry; Octavio Paz; The Labyrinth of Solitude; Postscript; Metaphors of History.

Fecha De ReCEPCIÓn: 22 de septiembre de 2014

FECHA DE ACEPTACIÓN: 25 de noviembre de 2014 



\title{
Octavio Paz y las metáforas de la historia
}

\author{
JaVier Rico Moreno \\ Facultad de Filosofía y Letras, UNAM \\ javierricom@gmail.com
}

\begin{abstract}
No sólo hemos sido expulsados del centro del mundo y estamos condenados a buscarlo por selvas y desiertos o por los vericuetos y subterráneos del Laberinto. Hubo un tiempo en el que el tiempo no era sucesión y tránsito, sino manar continuo de un presente fijo, en el que estaban contenidos todos los tiempos, el pasado y el futuro.
\end{abstract}

El laberinto de la soledad

En el observador común, una pirámide precortesiana y un laberinto provocan impresiones distintas. Plenamente visible, la primera se manifiesta imponente por las dimensiones y la geometría que la informan; quien la contempla desde la superficie suele entregarse a la tentación del ascenso, y experimentar esa extrańa sensación de mirar desde lo alto. El caso del laberinto es diferente: ya sea como edificación o como representación gráfica, ejerce en el observador la atracción del misterio o del enigma; para captar su forma es necesario experimentar el extravío al que incita; transitar por su interior y encontrar que inexplicablemente el camino elegido se cierra; regresar y buscar otro pasaje que, al fin, conduzca hasta su centro para luego iniciar el camino hacia la salida. ¿Guardan estas construcciones y la impresión que provocan alguna relación con la historia?

Guiado por una inquietud en torno a las formas de representación del pasado, hace ya algunos años emprendí la relectura de dos textos en prosa de Octavio Paz. Descubrí que al margen del tema de la identidad del mexicano y de las observaciones sobre el acontecer político de nuestro país, había en esos ensayos agudas reflexiones en las que el poeta aborda temas capitales de la teoría de la historia. Más aún: el estudio de esos textos desde una perspectiva historiográfica pone al descubierto una interpretación del pasado en la que se advierte el vínculo de la poesía con la historia. De alguna manera el corolario sería la apreciación 
del carácter metafórico que, en términos de la temporalidad, adquieren el laberinto y la pirámide.

\section{LAS FIGURAS Y LA HISTORIA}

La historia histórica implica, ante todo, movimiento, transformación; en ello radica la condición de posibilidad de toda narrativa histórica. En un acto más cercano a la poesía que a las cuestiones del método y la teoría, los historiadores modernos han acudido al lenguaje de las ciencias de la naturaleza en busca de imágenes para dotar de sentido a los momentos por los que suelen atravesar civilizaciones, sociedades y culturas: alba, amanecer, ocaso, primavera, otońo o cenit son sólo algunas. En un caso peculiar, el historiador francés Fernand Braudel ${ }^{1}$ buscó en los movimientos del mar las analogías que le permitieran hacer inteligibles los distintos tiempos históricos que su estudio sobre el Mediterráneo le había llevado a reconocer. Sugirió entonces que, a la mirada del observador, la superficie del mar ofrece pequeñas, aunque rápidas e intermitentes ondulaciones, que son como los acontecimientos; es el plano de la corta duración. Pero en un segmento más profundo, el desplazamiento de las aguas resulta mucho más lento, difícil de apreciar; a ese nivel corresponde el ritmo con el que cambian las estructuras económicas y sociales, los Estados, las civilizaciones; es el plano de la larga duración. Todavía a mayor profundidad, tiene lugar un movimiento de mucha más larga duración que equivale a las transformaciones de la relación del hombre con el medio, una especie de fenómenos geohistóricos. De la biología también provienen múltiples imágenes metafóricas cuya presencia en el discurso histórico se halla quizá más extendida: palabras como nacimiento (y renacimiento), muerte, florecimiento, evolución, adaptación o sobrevivencia, se incorporaron a los procesos de significación del pasado tratando de encontrar una analogía entre

\footnotetext{
${ }^{1}$ El Mediterráneo y el mundo mediterráneo en la época de Felipe II se publicó en 1949 y motivó el surgimiento de un nuevo tipo de historia: la historia de larga duración, cuyo objeto principal será el cambio de las estructuras. La obra no estuvo exenta de críticas; una de especial interés (por mostrar la aversión que historiadores de filiación cientificista expresan respecto de los vínculos de la historia con la literatura o la poesía) fue la del estadounidense Bernard Bailyn, quien lamentó que Braudel hubiera "confundido una respuesta poética al pasado con un problema histórico”. Citado por Burke: 44.
} 
los fenómenos de la vida y la historia (o viceversa). La pertinencia de todas esas figuras parece anclarse en su relación con la idea del tránsito desde un principio hasta un fin, o bien, en su referencialidad a un movimiento cíclico; en cualquier caso, el movimiento y el cambio son la constante.

Además de recurrir a imágenes metafóricas para designar un momento histórico, desde épocas remotas se ha buscado una representación visual que sintetice la forma en que acontece la historia. En la geometría euclidiana, la línea recta es una sucesión indefinida de puntos o de segmentos sobre un plano; no puede más que seguir una sola dirección, y sus extremos corresponden a principio y fin. Aunque la visión lineal de la historia (el acontecer de la humanidad como una línea que se extiende desde la creación hasta el fin de los tiempos) parece tener su origen en el pensamiento judeocristiano, fue a partir de la Ilustración que la figura de la línea recta se instaló plenamente como representación del movimiento histórico; ordenados con una cronología rigurosa, los acontecimientos y periodos históricos (cual puntos o segmentos) forman una secuencia que avanza en una dirección, sólo que la mentalidad ilustrada le añadió un sentido: el progreso (esa ambigua pero eficaz idea del mejoramiento de la vida social e individual). ${ }^{2}$

$Y$ sin importar si esa secuencia lineal asciende o desciende, en el plano personal tendemos a pensar nuestra vida (nuestra historia personal) casi siempre como una sucesión de hechos, lo que hace de cada biografía una línea temporal dividida en etapas (infancia, adolescencia, juventud...): nuestro pasado y nuestro futuro no escapan de esa linealidad en la cual lo que hemos hecho y padecido se enlazan en una serie indefinida de puntos o de segmentos sobre un plano, que es el espacio (el mundo) que habitamos. No es extraño que en la actualidad la construcción de líneas del tiempo sea uno de los recursos didácticos más comunes en la enseñanza de la historia (universal o nacional), lo que facilita una asociación mecánica entre lo que antecede y lo que sucede, entre causas y efectos.

No siempre ha sido así. En el ámbito del pensamiento mítico que acompaña a las civilizaciones antiguas, la secuencia de creación y des-

\footnotetext{
${ }^{2}$ Hay dos variantes de esta figura: la línea ondulada o la línea quebrada, mediante las cuales se trata de resaltar la sucesión de etapas de auge y decadencia, prosperidad y crisis; ninguna de ellas altera la imagen de la linealidad histórica.
} 
trucción, orden y caos, describe no una línea recta, sino una curva cerrada, una circunferencia, un círculo en el que principio y fin se tocan en algún punto. Esa representación cíclica del devenir no significa que los acontecimientos se repitan; en realidad, nunca son los mismos, lo que se reproduce es una secuencia. En el siglo xviII Giambattista Vico elaboró una visión de la historia distinta y semejante a la vez: en ella se advierte una repetición de la sucesión de tres edades (la divina, la heroica y la humana). ${ }^{3}$ El devenir de los seres humanos parece describir la combinación de dos movimientos uniformes y simultáneos: uno rectilíneo y otro rotacional. El resultado es una espiral; su extremo exterior atraviesa una y otra vez por las tres edades, pero cada ciclo implica formas superiores. Robin George Collingwood apuntó el carácter innovador de esa forma de imaginar la historia:

Primero, sostenía que ciertos periodos de la historia mostraban un carácter general que informaba todos los detalles particulares, carácter que, por otra parte, reaparecía en otros periodos históricos, de suerte que dos periodos distintos podían tener las mismas características generales, de donde era posible deducir uno de otro [...] Segundo, demostró que esos periodos semejantes tendían a repetirse en un mismo orden [...] Tercero, el movimiento cíclico de la historia no es una pura rotación de fases iguales; el movimiento es en espiral y no en círculo: la historia jamás se repite, sino que el retorno a cada nueva fase se reviste de formas distintas de las precedentes (133-134).

\section{EL LABERINTO}

En su vasta producción en prosa Octavio Paz aludió, al menos en un par de ensayos, a dos construcciones arquitectónicas de la antigüedad: el laberinto y la pirámide. Aunque estáticas e inmutables, persistentes en parte por su naturaleza pétrea, la intuición poética le permitió captar en el simbolismo de aquellas edificaciones cualidades idóneas para expresar su propia visión de la historia.

A diferencia de la línea recta, el círculo y la espiral, el laberinto, ya en su forma cuadrada o circular, es una figura compleja. Su carácter intrin-

${ }^{3}$ Principios de una ciencia nueva en torno a la naturaleza común de las naciones (1721), se reconoce como una importante obra de filosofía de la historia. 
cado le viene del entrecruzamiento de líneas paralelas y transversales que, obedeciendo a una extraña lógica, se interrumpen entre sí formando pasadizos irregulares; el entramado resultante cumple su propósito originario: la confusión y el extravío de quien trata de recorrerlo, así sea sólo con la mirada. De hecho su representación gráfica exige la vista de un observador que lo mira desde arriba. ¿De qué manera puede ser el laberinto una metáfora de la historia?

No deja de ser una paradoja que El laberinto de la soledad sea un texto por el que transitan múltiples personajes, ${ }^{4}$ ideas, imágenes y representaciones. Si en algunos casos se trata de figuras claramente visibles, en otros resultan discretas, casi una insinuación. Con esas presencias Octavio Paz emprendió un diálogo, a veces combativo, para hacer de su ensayo un entramado de intertextualidad multifacética en el que se aprecia la convergencia, entre otros, de tres elementos a partir de los cuales el laberinto se convierte en una imagen metafórica de la historia y el devenir: la estética de las correspondencias, la representación antropológica y la simbología del laberinto.

En el primer caso se trata de uno de los postulados del Romanticismo alemán, en particular la vertiente en la que convergen, entre otros, Novalis y Schlegel. En su reacción al racionalismo y al mecanicismo afianzados en la Ilustración, reivindicaron la necesidad de emprender una estetización de la realidad: aquello que no podía conocerse por medio de la razón resultaba accesible a la intuición estética. ${ }^{5} \mathrm{Al}$ mismo tiempo, se esforzaron por restaurar el valor del mito, la poesía y la religiosidad, de lo que resultó su intento de una repoetización del conocimiento y una remitologización del mundo. Albert Béguin destaca que los románticos, como antes los místicos, trataron de explicar el devenir del cosmos como el camino de retorno a la unidad perdida: a la unidad

${ }^{4}$ La lista es larga y diversa. Sin pretender una relación exhaustiva, cabe mencionar a filósofos (Samuel Ramos, Max Scheler, José Otega y Gasset, Georg Lukács), poetas (Antonio Machado, Ramón López Velarde, Xavier Villaurrutia, Paul Valéry, Jorge Cuesta), antropólogos y etnólogos (Amable Audin, Roger Caillois, Lucien Lévy-Bruhl, Mircea Eliade), sociólogos (Antonio Caso, Jean Gabriel-Tarde), historiadores (Edmundo O'Gorman, Arnold Toynbee). Muchos otros, como Marx, se resisten a una clasificación disciplinaria, y los personajes mitológicos son también abundantes.

${ }^{5}$ Kant había reconocido que el Absoluto resultaba inaccesible a la razón; incluso, las cosas en sí quedaban fuera de su alcance y sólo podían conocerse en su forma fenoménica. 
originaria había seguido la fragmentación, y cada ente llevaba en su interior un principio de individuación y de escisión, pero también un resabio de la unidad perdida y de su contrario: la unidad por restaurar; por tanto, la marcha hacia la reintegración era inevitable. Y eso no era todo: tras la fragmentación se había instaurado el mundo solar de la conciencia y la razón, pero era necesario recuperar poderes anteriores como la poesía, las matemáticas, la imaginación creadora y el sentido interno. Si el hombre es una imagen del cosmos, gracias a ese sentido interno - no perdido del todo, sino fragmentado y difuso- podía conocer al universo por analogía (cfr. Béguin 1954).

Conocer lo real, no por la razón sino por la intuición estética, equivalía a captar la existencia simbólica de todas las cosas de la naturaleza, que son un reflejo, oscuro y luminoso a la vez, de la realidad suprema. De lo anterior resulta un esquema de oposición, de lucha entre fuerzas antagónicas y complementarias, que marca el ritmo de la naturaleza. Entre todas las parejas de tendencias vitales hay una analogía que se funda en el ritmo del día y la noche, la oposición de los sexos, en los principios de la gravedad y de la luz, de la fuerza y la materia. Ritmo y analogía dieron lugar a una estética de las correspondencias.

De esa tendencia hacia una estetización de la realidad se distinguen varios elementos interpretativos que se entretejen en la representación histórica que Octavio Paz llevó a cabo en su ensayo; entre ellos: el recurso a las representaciones míticas, la intuición de la unidad original del mundo, la tensión entre la unidad perdida y la unidad por restaurar (tensión que resulta fundamental en la dialéctica de soledad y comunión), el carácter simbólico del mundo y el esquema dialéctico de su evolución, la naturaleza simbólica del hombre, y el recurso a la analogía, las correspondencias y el inconsciente como vías del conocimiento.

El segundo es la representación antropológica. Si bien es cierto que El laberinto de la soledad se ha leído muchas veces como un intento de descifrar la identidad del mexicano, el mismo Octavio Paz trató de corregir esa interpretación. ${ }^{6}$ En la parte inicial del ensayo (capítulos uno a cuatro), en efecto, emprendió una indagación acerca de la forma de ser

6 “Tal vez valga la pena aclarar (una vez más) que El laberinto de la soledad fue un ejercicio de la imaginación crítica: una visión y, simultáneamente, una revisión. Algo muy distinto a un ensayo sobre filosofía de lo mexicano, o a una búsqueda de nuestro pretendido ser [...] A mí me intrigaba (me intriga) no tanto 'el carácter nacional' como lo que oculta ese carácter: aquello que está detrás de la máscara” (Posdata en 1994: 269). 
(el carácter) del mexicano. Si en primera instancia es éste el personaje que transita por el laberinto, al mismo tiempo es el hombre en general. Semejante a cualquier ser humano, el mexicano expresa su forma de ser a través de su relación con el mundo, con el otro, con el trasmundo y consigo mismo (con su origen). Las cuatro dimensiones de esa relación no se reducen al espacio de la experiencia empírica; tienen lugar, fundamentalmente, en el ámbito de lo simbólico. Esta primera parte cierra con tres proposiciones: el sentimiento de orfandad como trasfondo de las tentativas políticas y los conflictos personales, la dinámica de lo abierto y lo cerrado (soledad y comunión) y la definición del mexicano como negación y ruptura.

Paz se dispuso entonces a explorar los vínculos entre esa forma de ser y la historia para descubrir que no hay entre ellas una relación de causa efecto, sino un proceso de interrelación: el carácter actúa sobre la historia del mismo modo que ésta modifica la forma de ser. En El laberinto se da por hecho que el mexicano es un ser social; sólo así puede oscilar entre soledad y comunión. No obstante, la afirmación más radical es la que se refiere a la historicidad del ser humano. Parece inobjetable la adhesión de Paz al historicismo vitalista de Ortega y Gasset. El filósofo español había denunciado en Historia como sistema que la ciencia había fracasado en su búsqueda de la esencia humana simplemente porque el ser humano no tiene una naturaleza, lo que tiene es historia. Pero la historicidad del hombre en la que piensa Paz es radical: el hombre es historia. "El hombre no sólo es fruto de la historia y de las fuerzas que la mueven, como se pretende ahora; tampoco la historia es resultado de la sola voluntad humana - pretensión en que se funda, implícitamente, el sistema de vida norteamericano. El hombre, me parece, no está en la historia: es historia" (El laberinto en 1994: 58). La historia no es aquí un continuo temporal que antecede siempre al presente del hombre; no es el pasado la fuerza o el ímpetu y el presente el movimiento resultante. Historia es pasado, presente y futuro encarnados en el ser humano. Si no posee una naturaleza o carácter inmutable, sino que el cambio y la indeterminación son la única constante de sus actitudes vitales, entonces el ser humano se define como posibilidad. Es fácil advertir que tal manera de concebir la historicidad del hombre no se adecua plenamente a una visión lineal de la historia.

En esa historicidad se manifiesta su carácter simbólico, pero también su estructura psíquica: si en el transcurrir de su vida elabora y traduce 
símbolos, también crea fantasmas, algunas veces a partir de vestigios del pasado, o recurre a variados mecanismos psicológicos de defensa. Hay en él una realidad psíquica que se muestra o se oculta. Se trata de "[...] la existencia de un psiquismo inconsciente — tan inconsciente como fundamental — en el cual permanecen 'enterradas', pero no por completo destruidas, las distintas edades psíquicas, sobre todo las más arcaicas" (González: 59; entrecomillado de la autora). Tanto El laberinto de la soledad como Posdata dejan ver una analogía fundamental en la interpretación histórica de Octavio Paz: la historicidad, el simbolismo y el psiquismo presentes en la vida de un individuo, se encuentran también en la historia de una sociedad, un pueblo o una cultura.

con ella [la expresión el otro México] pretendo designar a esa realidad gaseosa que forman las creencias, fragmentos de creencias, imágenes y conceptos que la historia deposita en el subsuelo de la psiquis social, esa cueva o sótano en continua somnolencia y, asimismo, en perpetua fragmentación [...] la existencia en cada civilización de ciertos complejos, presuposiciones y estructuras mentales generalmente inconscientes y que resisten con terquedad a la erosión de la historia y a sus cambios (Posdata en 1994: 305).

El tercer elemento al que haré referencia es la simbología del laberinto. Si bien, por su etimología, laberinto significa hacha doble, en general, designa "un lugar artificiosamente formado de calles para que, confundiéndose el que está adentro, no pueda acertar con la salida"? En Occidente se tiene el registro de cuatro laberintos de la antigüedad: el de Moeris, en Egipto; ${ }^{8}$ Cnosos y Lemmos, en la Grecia insular; y el que los etruscos construyeron en Clusium, en la parte inferior de la tumba del rey Porsena. De todos ellos, el construido por Dédalo para confinar al Minotauro en la soledad y del cual Perseo sólo podría salir

${ }^{7}$ Junto con el laberinto, el hacha doble es uno de los símbolos esenciales del culto cretense; alude a la revelación del centro existencial (cfr. Cirlot: 241-242).

${ }^{8}$ Sin ocultar la impresión que le provocara, Herodoto dejó el testimonio de su visita a Moeris: "Compónese de doce palacios cubiertos, contiguos unos a otros y cercados todos por una pared exterior, con las puertas fronteras entre sí; seis de ellos miran al Norte y seis al Mediodía. Cada uno tiene duplicadas sus piezas, unas subterráneas, otras en el primer piso, levantadas sobre los sótanos, y hay mil quinientas de cada especie, que forman entre todas tres mil" (179). Es factible que el de Moeris se erigiera como el laberinto arquetípico de la Antigüedad. 
con ayuda del hilo de Ariadna, es sin duda el de mayor resonancia simbólica en la cultura occidental.

Desde entonces, el simbolismo del laberinto se ha hecho complejo y diverso; de modo que pueden identificarse al menos cinco significados distintos. El primero radica en lo complicado e intrincado de su construcción, y la consecuente dificultad que entraña su recorrido, tanto de ida como de vuelta; es un espacio para el extravío y la confusión, lo que le imprime un cierto poder de atracción. En segundo lugar, el laberinto se asocia a la idea de tránsito, viaje o peregrinación, y como tal se insertó en la simbología de centros del culto cristiano. ${ }^{9}$ Dicho significado fue común a partir del siglo XII, cuando resultó imposible emprender las peregrinaciones a la Tierra Santa. Los constructores medievales lo representaron en el piso de catedrales, iglesias y abadías en forma de círculos o polígonos concéntricos interrumpidos en ciertos puntos; bajo esta forma constituye el "Chémin à Jérusalem" (los fieles debían recorrerlo de rodillas, o bien, seguir con los dedos el trazo grabado en columnas). En el contexto de la construcción de algunas catedrales góticas, como en el caso de Notre Dame, el laberinto pasó a formar parte de una compleja imagen del mundo.

La tradición hermética, que reconoce en el arte gótico el ar got, "el arte de la Luz o el Espíritu" (Fulcanelli: 53), ve en esos laberintos "[...] una figura cabalística que se encuentra al principio de ciertos manuscritos alquímicos y que forma parte de las tradiciones mágicas atribuidas al nombre de Salomón". ${ }^{10}$

En la dimensión psicoanalítica, y de acuerdo con Paul Diel —autor de Symbolisme dans la mythologie grecque - el laberinto simboliza "el inconsciente, el error y el alejamiento de la fuente de vida" (id.). En este sentido, implica siempre un recorrido por el interior de sí mismo, hacia las profundidades del inconsciente a las que se puede acceder sólo tras largos rodeos, hasta encontrar la unidad perdida del ser. En el ámbito de las imágenes asociadas al cambio y al devenir histórico, Chevalier sugiere que puede verse al laberinto como la combinación de la espiral (el perpetuo devenir sin término, lo indeterminado) y la trenza

${ }^{9}$ La primera inclusión de una forma laberíntica en una iglesia se encuentra en un mosaico de la catedral de Orléansville (El-Asnam, hoy Ech Cheliff, al norte de Argelia), del siglo iv d. C.

${ }^{10}$ Marcellin Berthelot, La Grande Enciclopédie. Art. Labyrinthe, t. XXI, p. 703; citado por Fulcanelli: 59. 
(el eterno retorno). De ahí que la imagen estática, tanto del laberinto (construcción arquitectónica fija en el espacio), como la del personaje encerrado en él, se sustituya por el movimiento que implica su recorrido (Chevalier y Gheerbrant: 620-622).

Se encuentra, por último, la imagen del laberinto como un viaje iniciático que contiene la ambigüedad de lo abierto y lo cerrado: permite el acceso a quien emprende la búsqueda del centro, pero se mantiene cerrado a quien no está preparado para ello. Mircea Eliade ha indicado que la función primordial del laberinto es la de preservar el centro, lo cual lo convierte en una prueba semejante a la lucha contra el dragón como acceso iniciático a la sacralidad, la inmortalidad y la realidad absoluta. Por otra parte, señala Cirlot, el laberinto "se puede experimentar en la realidad de los dédalos de una ciudad desconocida, en especial, de las ciudades antiguas u orientales. Nerval tuvo la obsesión del laberinto y en sus obras prueba haberlo experimentado de este modo, como pérdida en un mundo que es equivalente al caos" (274).

El laberinto de la soledad describe - y relata al mismo tiempo- el tránsito del mexicano por el laberinto en el que consisten su vida y su historia. Ambas transcurren en la oscilación entre los opuestos de una estructura binaria. De una parte se aprecia una relación que puede ser de correspondencia o no correspondencia entre la forma y la realidad, entre la razón y el instinto. Por la otra, vida individual e historia colectiva siguen el camino de una oscilación entre opuestos en el plano del ser: soledad y comunión, ocultamiento y revelación, cierre y apertura, autenticidad e inautenticidad.

3. LA PIRÁMIDE

...esa tarde la historia visible desplegó, a la manera de un códice precolombino, nuestra otra historia, la invisible. La visión fue sobrecogedora porque los símbolos se volvieron trasparentes.

Posdata

En Posdata, publicado casi veinte años después que El laberinto..., Paz emprendió otra audaz interpretación de la historia al revelar un vínculo 
profundo entre un pasado remoto (el mundo mesoamericano, particularmente el de los aztecas) y aquel ahora (el México posrevolucionario de finales de los ańos sesenta). Si bien sus reflexiones sobre el pasado y el presente se condensan en torno al simbolismo de la pirámide prehispánica, la imagen de la historia que se aprecia en ese otro ensayo asemeja la escena de una pintura barroca en la que predomina el claroscuro.

Al igual que en El laberinto..., en Posdata Paz despliega una prosa poética mediante la cual expone una serie de ideas que se sitúan con toda legitimidad en el campo de la teoría de la historia, si no con la sistematicidad que los teóricos y los historiadores desearían, sí con la profundidad que convoca a pensar ciertos aspectos de la historicidad del hombre de un modo radical. De nueva cuenta, sus reflexiones se hallan ineludiblemente atadas a la dimensión simbólica, tanto del mundo como de la vida del hombre en la que muestra una convicción plena. Así, reitera la necesidad de que todo intento de comprensión de lo humano debe pasar por la observación de las actitudes vitales que se muestran en su relación con el mundo, el trasmundo, el otro y el yo; ellas conforman "[...] realidades que han sido olvidadas o negadas de un modo terco y obtuso por el mundo moderno y que, no obstante, reaparecen ahora con mayor energía" (Posdata en 1994: 303). No menos importante es su insistencia en la analogía por medio de la cual se advierte que algunos procesos psíquicos pueden ser comunes tanto al individuo como a las civilizaciones; en particular, el hecho de que "[...] la persistencia de traumas y estructuras psíquicas infantiles en la vida adulta es el equivalente de la permanencia de ciertas estructuras históricas en las sociedades. Tales estructuras son el origen de esos haces de rasgos distintivos que son las civilizaciones. Civilizaciones: estilos de vivir y morir" (289).

Hay también una ampliación de su idea de que el hombre no tiene historia, sino que es historia, lo cual, entre otras cosas permite que el problema de la identidad sólo se resuelva de manera relacional: "[...] no somos nada, excepto una relación, algo que no se define sino como parte de una historia" (271). La afirmación de que el hombre tiene historia obliga a reconocer que se trata de dos entidades distintas, y entonces la historia debe ocupar un tiempo (un antes) y un lugar (afuera) distintos a los del ser humano; pero al sostener que el hombre es historia, entonces ésta ya no resulta algo externo a él, sino algo constitutivo de su ser; por eso no tiene un tiempo y un espacio que le sean ajenos. 
Al diferenciar la historia como realidad y la historia como registro de lo sucedido, y como si tratara de conciliar a Heráclito con Parménides, al cambio con la permanencia en la historia, Paz sostiene:

$\mathrm{Ni}$ adentro ni afuera, ni antes ni después: el pasado reaparece porque es un presente oculto. Hablo del verdadero pasado que no es lo mismo que "lo que pasó": las fechas, los personajes y todo eso que llamamos historia. Aquello que pasó efectivamente pasó, pero hay algo que no pasa, algo que pasa sin pasar del todo, perpetuo presente en rotación. La historia de cada pueblo contiene ciertos elementos invariantes o cuyas variaciones, de tan lentas, resultan imperceptibles (305-306).

A muy corta distancia de estas reflexiones, con el impulso del giro lingüístico, algunos teóricos de la historia habían emprendido un desplazamiento de sus estudios sobre la naturaleza del conocimiento histórico y las obras en las que se condensa. ${ }^{11}$ Convencidos de que el trabajo de los historiadores consiste fundamentalmente en una lectura especializada de textos, hicieron a un lado las cuestiones metodológicas y se concentraron en el plano discursivo. ${ }^{12}$ No sin encontrar resistencia, abrieron una línea hermenéutica a través de la cual podía constatarse que la tarea del historiador era básicamente de interpretación y que, más que con hechos, trabaja con discursos; la confianza en la verdad objetiva del conocimiento histórico parecía desvanecerse sin remedio; cada presente hará necesaria una reescritura del pasado, no sólo en función del hallazgo de nuevos documentos, sino por distintas interpretaciones que se originan en nuevos horizontes histórico culturales. Por otra parte, la crítica valorativa dejó de centrarse en los hallazgos, datos o documentos incorporados en una obra histórica, para dar lugar a la retórica y las formas de composición. Con ello se evidenciaría que historiografía y literatura se hallan separadas apenas por la delgada línea que forma la pretensión de verdad de los historiadores. Aunque el lenguaje era ya una presencia constante en la trayectoria intelectual de Octavio Paz, en Posdata advierte sobre una relación, triple e ineludible,

${ }^{11}$ Sería el caso, por ejemplo, de Hayden White, Paul Ricoeur, Hans G. Gadamer, entre otros.

${ }^{12}$ Esto no significa que ya no se abordaran los temas metodológicos, sino que, en última instancia, éstos se subordinaron o se incorporaron a los procesos interpretativos $\mathrm{y}$ formales en la elaboración de representaciones del pasado. 
en la cual la interpretación se convierte en el medio significante en -y entre- la vida y la historia. La agudeza de su observación y su relación con el campo de la teoría y la filosofía de la historia ameritan bien una cita in extenso:

la historia nos obliga a vivirla: es la substancia de nuestra vida y el lugar de nuestra muerte. Entre vivir la historia e interpretarla se pasan nuestras vidas. Al interpretarla, la vivimos: hacemos historia; al vivirla, la interpretamos: cada uno de nuestros actos es un signo. La historia que vivimos es una escritura; en la escritura de la historia visible debemos leer las metamorfosis y los cambios de la historia invisible. Esa lectura es un desciframiento, la traducción de una traducción: jamás leeremos el original. Cada versión es provisional: el texto cambia sin cesar (aunque quizá siempre dice lo mismo) y de ahí que de tiempo en tiempo se descarten ciertas versiones a favor de otras que, a su vez, antes habían sido descartadas. Cada traducción es una creación: un texto nuevo (307).

Tales observaciones derivan en la ampliación del carácter simbólico de la realidad a la historia y a la idea de la coexistencia entre una historia visible y otra oculta: "Todas las historias de todos los pueblos son simbólicas; quiero decir: la historia y sus acontecimientos y protagonistas aluden a otra historia oculta, son la manifestación visible de una realidad escondida" (307).

Luego de analizar la revuelta estudiantil de $1968,{ }^{13}$ así como las contradicciones y obstáculos de las aspiraciones desarrollistas en América Latina, Paz se propuso emprender la crítica de uno de los aspectos del proceso histórico y político de México, convencido de que la política es parte de la historia y, por tanto, la observación crítica de ésta implica también un cuestionamiento político y moral. Ese examen se articulará en torno al simbolismo de la pirámide, en particular con la dimensión que le añaden los aztecas durante el periodo de su dominación.

${ }^{13}$ Paz ve en aquel acontecimiento la revuelta que un sector social marginado por la sociedad tecnológica, los estudiantes, protagonizó en distintas regiones del mundo en 1968. Sin dejar de lado las diferencias visibles de aquel fenómeno en regiones como Europa oriental, Francia, Estados Unidos y México, identificó en la crítica juvenil su común denominador. Sus apreciaciones del perfil sociocultural del sector juvenil a partir de su aquí (los campus universitarios) y su ahora (las contradicciones de la modernidad), coinciden con las que, veinticinco años después, expuso el historiador Eric Hobsbawm al estudiar la revolución cultural de la década de los sesenta (cfr. 1995: 322-345). 
En términos generales, se ha reconocido en la pirámide una representación de la tierra emergiendo de las aguas primordiales (y, por tanto, de la creación), un símbolo ascensional y de poder, o bien, el espacio de encuentro del cielo y la tierra (Chevalier y Gheerbrant: 837-839). ${ }^{14}$ Aunque Paz tiene presente estas atribuciones de la pirámide, tratará de enfatizar el sentido específico de su imagen entre los aztecas: como metáfora geométrica del cosmos, es decir, como una representación del orden del espacio y del movimiento, y como escenario del ciclo al que da lugar el juego de los dioses: creación, destrucción y recreación por medio del sacrificio. Lo que la pirámide representa en el plano cosmológico tiene su correspondencia en lo político: una estructura de dominación tan sólida que se mantendrá invariable a través de la Conquista, la Independencia y la Revolución:

Si desde el siglo xIv hay una secreta continuidad política, ¿cómo extrañarse de que el fundamento inconsciente de esa continuidad sea el arquetipo religioso-político de los antiguos mexicanos: la pirámide, sus implacables jerarquías y, en lo alto, el jerarca y la plataforma del sacrificio? Al hablar del fundamento inconsciente de nuestra idea de la historia y de la política, no pienso nada más en los gobernantes sino en los gobernados (Posdata en 1994: 310).

Ya en el quinto capítulo de El laberinto... ("Conquista y Colonia"), se advierte que Paz estaba al tanto de algunas investigaciones recientes sobre las culturas mesoamericanas, ${ }^{15}$ y no es de extrañar que en Posdata exponga sus ideas en torno a la forma en que los aztecas forjaron una especial relación entre historia y política como basamento de su hegemonía. En un horizonte en el que predominaba $-\mathrm{y}$ en buena medida sigue predominando- una visión idealizada de aquella cultura, sus afirmaciones sobresalen por el ejercicio de la crítica. Los aztecas, señala, se apropiaron de una historia mítica y una cosmología (las de los tolte-

${ }^{14}$ Esta simbología se centra, básicamente, en las pirámides del antiguo Egipto.

${ }^{15}$ En aquel ensayo hace referencia, aunque sin citarlo, al concepto de Mesoamérica, que poco antes había acuñado Paul Kirchhoff; también muestra su lectura de Jacques Soustelle, de quien seguramente leyó, antes de su edición en español, el estudio sobre el pensamiento cosmológico de los antiguos mexicanos; por último, debe referirse la obra de Arnold Toynbee, que si bien no trata sobre las culturas mesoamericanas, incluye algunas de ellas en su clasificación según los tipos de filiación histórica. 
cas) y la adecuaron a sus propósitos de dominación: "Religión solar e ideología expansionista, heroísmo sobrehumano e inhumano realismo político, locura sagrada y fría astucia, sacrificio y pillaje, entre tales extremos se movía el ethos azteca" (314).

Más que en lo arquitectónico, Paz descubre una continuidad histórica que se localiza en el ámbito de la política y la moral; la pirámide y el tlatoani son imagen arquetípica, representación simbólica de la permanencia de una estructura de dominación que se transmite a los siguientes periodos de la historia de México. Virreyes, caudillos y presidentes son sus herederos. Siempre por el camino de las analogías, sugiere una correspondencia entre la usurpación que hizo el PRI de la herencia revolucionaria con la usurpación de la herencia tolteca que llevaron a cabo los aztecas; entre la figura del tlatoani y su poder impersonal y la del presidente, asociados ambos a un tiempo cíclico. Por eso el 2 de octubre es como la revelación de una historia oculta; una reactualización del sacrificio con el propósito de mantener el poder: escena de un cuadro barroco en el momento en que las sombras se desvanecen y dejan al descubierto su parte oculta.

Producto de la combinación de la intuición poética y la agudeza intelectual que distinguen su obra en prosa, Octavio Paz hizo del laberinto y la pirámide dos imágenes de extraordinaria riqueza para la imaginación histórica (que es también imaginación creadora), de la que parece depender (tanto o más que de las cuestiones de teoría y método) la posibilidad del discurso histórico. Tanto El laberinto de la soledad como Posdata constituyen el reencuentro de la poesía con la historia; en ambos textos se descubre un hacer poético que se despliega en la creación de imágenes densamente significantes mediante las cuales se crea una interpretación del pasado. Tal incursión de la actividad poética en el ámbito de la historia invita, a la vez, a reconocer lo que de poético tiene siempre la actividad de los historiadores, tan cercana a la literatura.

\section{Bibliografía}

BÉGuin, Albert. El alma romántica y el sueño. Ensayo sobre el romanticismo alemán y la poesía francesa. Traducción de Mario Monteforte. México: Fondo de Cultura Económica, 1954. 
Burke, Peter. La revolución historiográfica francesa. La escuela de los Annales:1929-1989. Traducción de Alberto Luis B. Barcelona: Gedisa, 1993.

Cirlot, Juan Eduardo. Diccionario de símbolos. Madrid. Ediciones Siruela, 1997.

Chevalier, Jean y A. Gheerbrant. Diccionario de los símbolos. Traducción de Manuel Silvar y Arturo Rodríguez. Barcelona: Herder, 1988.

Collingwood, R. G. Idea de la historia. $3^{\text {aa }}$. edición. Prefacio e introducción de Jan van der Dussen, traducción de Edmundo O'Gorman y Jorge Hernández C. México: Fondo de Cultura Económica, 2004.

Diccionario de hermenéutica. Dirigido por Andrés Ortiz-Osés y P. Lanceros, tercera edición. Bilbao: Universidad de Deusto, 2001.

FulCANelli. El misterio de las catedrales, s.p.i., Rotativa.

GonzÁlez, Juliana. "Una lectura filosófica de El laberinto de la soledad", en Memoria del coloquio internacional "Por El laberinto de la soledad, a 50 años de su publicación". México: Fundación Octavio Paz / Fondo de Cultura Económica, 2001: 57-72.

Heródoto. Los nueve libros de la historia. Traducción de Bartolomé Pou. Buenos Aires: El Ateneo, 1961.

Hobsbawm, Eric. Historia del siglo XX (1914-1991). Traducción de J. Faci, J. Ainaud y C. Castells. Barcelona: Crítica, 1995.

Ortega y Gasset, José. Historia como sistema. Madrid: Espasa-Calpe, 1971.

Paz, Octavio. El laberinto de la soledad y Posdata, en Obras completas, vol. 8. México: Fondo de Cultura Económica, 1994.

Toynbee, Arnold. Estudio de la historia. Compendio de D.C. Somervell, traducción de Luis Grasset. Madrid: Alianza, 1971. 